\title{
Metodologia para detecção de áreas socioambientalmente vulneráveis: o caso do distrito do Campeche, no município de Florianópolis - SC, Brasil
}

\begin{abstract}
Resumo
A sociedade contemporânea lida constantemente com questões intensas de mudanças climáticas e influências destas em diversas partes do planeta, com diversos reflexos nas regiões costeiras. Minimizar os impactos ambientais e efeitos no ecossistema em áreas zoneadas conceitualmente opostas, então sobrepostas ou limitantes geograficamente, é um desafio para o poder público, seja pelo prisma do planejador, da gestão do território, entre outros agentes do espaço geográfico. É urgente que mecanismos para otimização da identificação dessas áreas sejam pesquisados e promovidos, uma vez que os desdobramentos da passividade desses equívocos ou falhas entre zoneamentos territoriais podem incidir em impactos socioambientais e socioeconômicos incomensuráveis aos atores locais. Esta pesquisa abordará, portanto, um método para a identificação de áreas potenciais de riscos de conflitos socioambientais, alicerçado por técnicas de geoprocessamento, como a análise espacial. $O$ método proposto foi aplicado no distrito do Campeche (Florianópolis - SC), lugar passivo dessas discussões e influenciado (in)diretamente por mudanças climáticas e discussões ambientais.
\end{abstract}

Palavras-chave: Política ambiental. Gerenciamento costeiro. Planejamento urbano. Análise espacial. Campeche (Florianópolis, SC).

\section{Eduardo Schmidt Longo}

Mestre e Doutorando em

Planejamento Territorial e

Desenvolvimento Socioambiental

pela Universidade do Estado de

Santa Catarina - PPGPLAN,

FAED/UDESC.

Brasil

eduardosl.geo@gmail.com

\section{David Valença Dantas}

Doutor em Oceanografia pela

Universidade Federal de

Pernambuco - UFPE. Professor

da Universidade do Estado de

Santa Catarina - UDESC, Campus

Laguna. Professor do Programa

de Pós-Graduação em

Planejamento Territorial e

Desenvolvimento Socioambiental

- PPGPLAN, FAED/UDESC.

Brasil

david.dantas@udesc.br

\section{Para citar este artigo: \\ LONGO, Eduardo Schmidt; DANTAS, David Valença. Metodologia para detecção de áreas socioambientalmente vulneráveis: o caso do distrito do Campeche, no município de Florianópolis - SC, Brasil. PerCursos, Florianópolis, v. 21, n.46, p. 83 -112, maio/ago. 2020.}

DOI: $10.5965 / 1984724621462020083$

http://dx.doi.org/10.5965/1984724621462020083 


\title{
Methodology for the detection of socio- environmentally vulnerable areas: the case of the district of Campeche, in the municipality of Florianópolis - SC, Brazil
}

\begin{abstract}
Contemporary society constantly deals with intense climate change issues and its influences on different parts of the planet, with different effects on coastal regions. Minimizing environmental impacts and effects on the ecosystem in conceptually opposed zoned areas, then overlapping or limiting geographically, is a challenge for public authorities, whether from the planner's perspective, from the management of the territory, among other agents of the geographical space. It is urgent that mechanisms to optimize the identification of these areas be researched and promoted since the unfolding passivity of these misunderstandings or failures between territorial zonings can affect socio-environmental and socioeconomic impacts that are immeasurable to local actors. Therefore, this research will address a method to identify potential areas of risk to socioenvironmental conflicts based on geoprocessing techniques, such as spatial analysis. The proposed method was applied in the Campeche district (Florianópolis - SC), a passive place of these discussions and influenced (in)directly by climate changes and environmental discussions.
\end{abstract}

Keywords: Environmental policy. Coastal management; Territorial planning. Spatial analysis. Campeche (Florianópolis - SC). 


\section{Introdução}

As zonas costeiras estão sob forte pressão de atividades antropogênicas, e representam a estreita zona de transição entre a terra e o mar, caracterizando-se por seus ecossistemas intensamente diversos, além de possuírem as maiores taxas de crescimento populacional e urbanização em relação às médias territoriais (HANSEN, 2014).

Um dos principais desafios em regiões costeiras resulta da fragmentação e perda das chamadas zonas úmidas das marés, referentes a sua compressão costeira (BORCHERT et al., 2018 apud MARTíNEZ-LÓPEZ, 2019). Em geral, esse fenômeno de "aperto costeiro" é causado por alguns efeitos combinados, como o aumento do nível do mar - ou aumento do nível da água devido à hidromorfologia - concomitante ao impulso do desenvolvimento urbano e rural (PONTEE, 2013), onde uma desvirtuada aceleração da antropização pode impactar por tais fenômenos.

De acordo com o Painel Intergovernamental sobre Clima - IPCC (2001 e 2007), o aquecimento e as mudanças no sistema climático tornam-se fato e os impactos dessa mudança climática, especialmente na temperatura das águas, precipitações desregulares, variações de níveis do mar, entre outros, trazem aos sistemas costeiros um aumento do nível das incertezas e uma preocupação crítica aos países costeiros (INOUYE, 2015).

Em uma perspectiva físico-geográfica, é sabido que o ambiente costeiro caracteriza-se por suas especificidades muito particulares, advindas e geradas intrinsecamente por dinâmicas da interação entre diversos processos (continentais, flúvio-lacustrinos, oceânicos e atmosféricos) - ocorridas em um mesmo padrão de recorte geográfico (MORAES, 2007, p. 22).

Dessa maneira, as zonas costeiras são o abrigo de um mosaico de ecossistemas de alta relevância ambiental, onde diante do extenso litoral brasileiro, é possível verificar a presença [ou vestígios de ter havido] de mangues, restingas, campos de dunas, estuários, recifes de corais, entre outros ambientes imprescindíveis do ponto de vista ecológico (DIEGUES, 2002, p. 15-18). Ademais, se faz necessário salientar que é na zona costeira que 
se localizam as maiores manchas residuais de Mata Atlântica e toda sua biodiversidade (MORAES, 2007, p. 100).

Logo, a associação dessas especificidades qualifica o espaço litorâneo como algo raro, caro e quisto, sendo a localização costeira privilegiada e dotada de qualidades geográficas particulares. Igualmente, são essas particularidades que tornam o ambiente costeiro além de um espaço habitado, um território debatido e conflituoso (CAVALCANTE, 2018; MORAES, 2007, p. 22).

Em termos de planejamento urbano e territorial, o plano diretor é o instrumento legal que normatiza o uso e ocupação do solo nos municípios (BRASIL, 2001). Da mesma forma, o Zoneamento Ecológico Econômico Costeiro (ZEEC) é uma espécie de zoneamento que conceitua territórios por critérios determinantes, através de seus potenciais e limites de uso, condicionando assim a gestão das áreas costeiras brasileiras (SANTA CATARINA, 2006). Por meio desses zoneamentos, fragmentam-se conceitualmente os substratos geográficos em zonas específicas, sendo possível compatibilizar a ocupação e a infraestrutura no espaço urbano, em adequação a um meio ambiente ecologicamente equilibrado, valendo-se então dos artigos 182, 183 e 225 da Constituição Federal (BRASIL, 1988).

Todavia, há possibilidade de existência de uma espécie de incongruência entre determinados zoneamentos (ex.: urbanos e ambientais) sobrepostos (ou limitantes), tornando-os uma espécie de "vizinhos contraditórios" em relação as suas finalidades territoriais, colocando em risco as paisagens, o ecossistema e o espaço nas regiões costeiras, além de poder intensificar e contribuir para variações de microclima, poluição ambiental da região, entre outros. A figura 1 representa de forma apenas didáticoelucidativa o que seriam essas incongruências em termos de ambientes vizinhos, onde a contradição se denota quando há um fator legal que legitime construções então sobrepostas ou coladas a ambientes que, também ratificados por outro ordenamento do território, se dispõem a proteger o meio ambiente natural, ou minimamente deveriam respeitar uma espécie de transição paulatina paisagística entre aquelas edificações e transformações e os ambientes naturais do local. 
Figura 1 - Sobreposição de camadas conflitantes conceitualmente

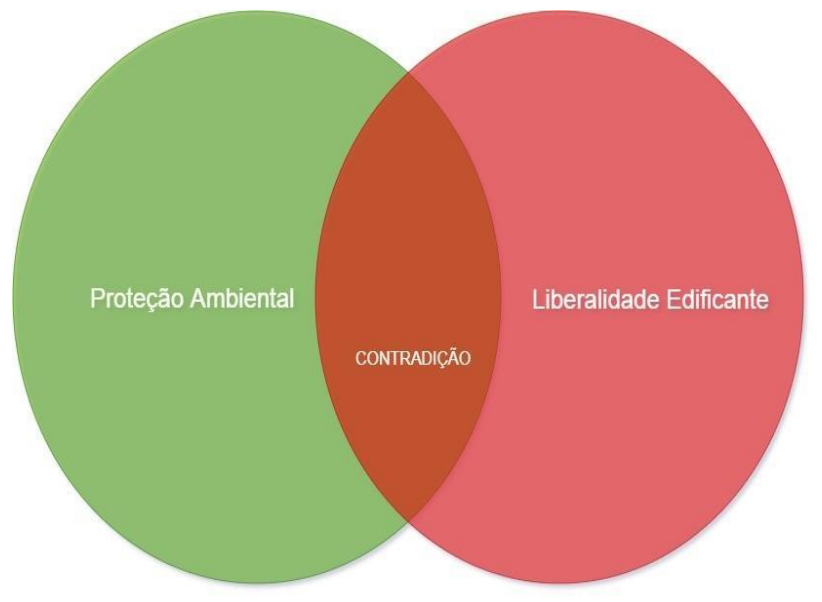

Fonte: Autor.

Para que essas demarcações sejam averiguadas diante de parâmetros de análises técnicas, e o poder público possa focalizar suas ações onde denote maior necessidade, é possível a utilização de métodos de geoprocessamento, para que auxiliem na tomada de decisões, localizando possíveis áreas de maior predisposição a conflitos socioambientais nas zonas costeiras, e assim buscar evitar ou dirimir esses futuros [ou já presentes] problemas socioambientais (HANSEN; FUGLSANG, 2014).

O termo Geoprocessamento refere-se ao processamento de dados com referência geográfica (dados geoespaciais). Tal processamento é executado a partir de um conjunto de tecnologias voltada à coleta e tratamentos de dados em Sistemas de Informação Geográfica (SIG) (DRUCK et al., 2004). O tratamento desses dados envolve a aplicação de métodos, técnicas e modelos matemáticos que permitem a geração de informações e a construção de conhecimentos. Entre os procedimentos mais utilizados no geoprocessamento está a Análise Espacial (CAMARA; DAVIS; MONTEIRO, 2001).

O uso de modelos computacionais e métodos para simulação ascendem a questões relacionadas a uma democracia "sociotécnica" e sua necessidade de mais instrumentos tecnológicos aplicados nas políticas públicas - ou seja, meios operacionais que permitem extrair conhecimentos sobre localizações e fluxos, hierarquias e 
especializações funcionais, entre outros, podendo dessa forma contribuir para a compreensão dos fenômenos sociais -, pois informação e conhecimento, concomitantes à complexidade e à duração do processo de planejamento territorial costeiro, podem intensificar as questões críticas (GOURMELON; LE GUYANER; FONTENELLE, 2014).

Exemplo desses tipos de aplicações tecnológicas por políticas públicas é a utilização de sistemas para participação social e de informação geográfica como estratégias baseadas no desenvolvimento sustentável, de acordo com a Cúpula da Terra AGENDA 21 (UNITED NATIONS, 1992), que defende o uso de melhores capacidades de modelagem para o exame de todos os usos da terra de maneira integrada, para minimizar conflitos, além da vinculação do desenvolvimento socioeconômico com a devida proteção e melhoria ambiental (PETTIT, 2005).

Portanto, como objetivo desta pesquisa, através do método de geoprocessamento chamado análise espacial, buscar-se-á consistência na localização de indícios de conflitos socioambientais a partir de evidências entrezoneamentos contraditoriamente expostos em zonas divergentes de necessidades e cuidados.

\section{Materiais e métodos}

A pesquisa foi realizada no distrito administrativo do Campeche, localizado ao sul da Ilha de Santa Catarina, Município de Florianópolis - SC, Brasil (Figura 2). Conhecida por ser uma região costeira com grande popularidade por suas belezas naturais, mas também pelos recentes fenômenos de transformações na paisagem a partir de seu intenso uso e apropriação do solo, como por exemplo, o surgimento de condomínios de praia em detrimento das casas locais de poucas décadas atrás.

A população estimada do Município de Florianópolis (SC) é de 508.826 habitantes, segundo o IBGE, bem como, a área territorial do município de 674.844 km² (IBGE, 2020). 
Figura 2 - Mapa de localização do Distrito do Campeche, Florianópolis - SC

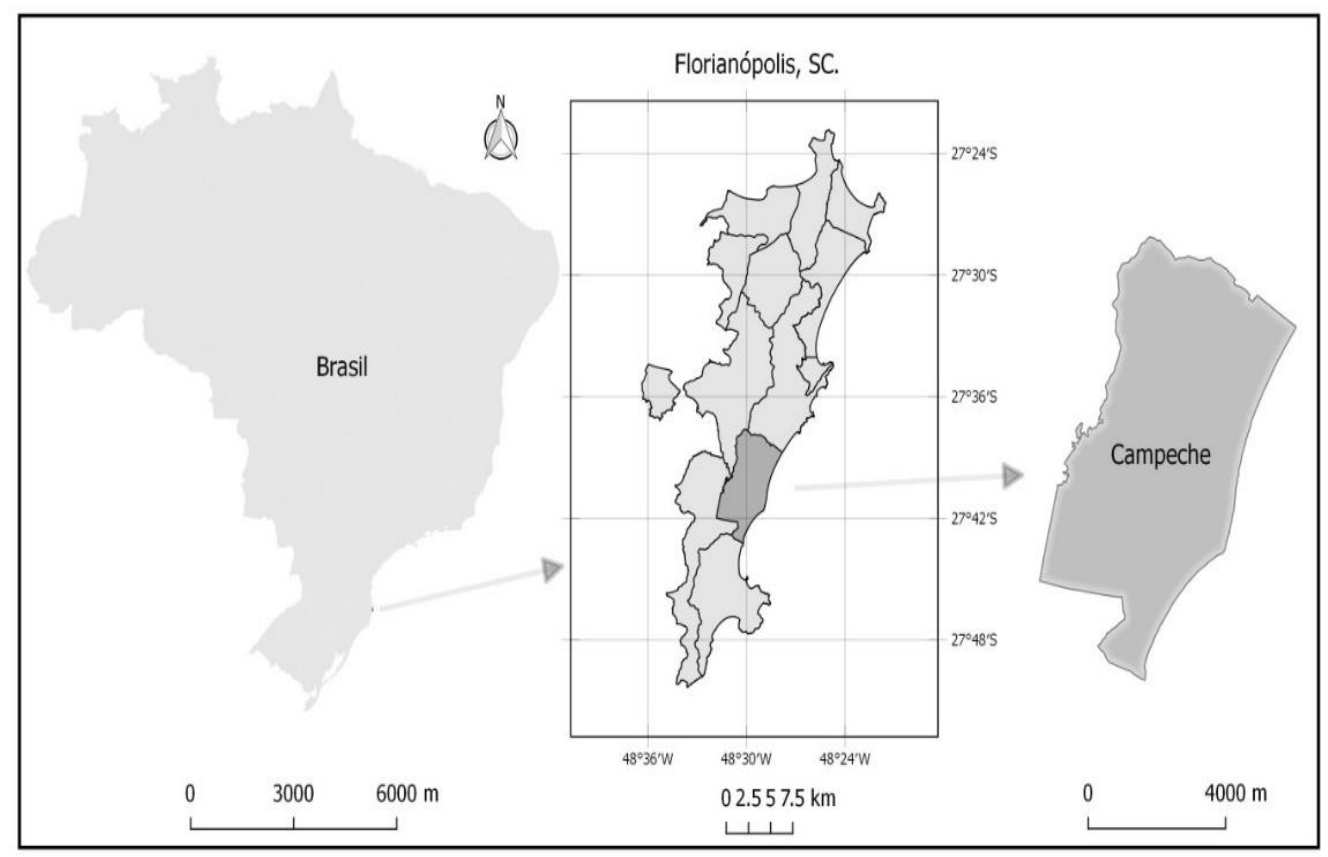

Fonte: Autor.

Por conta de conflitos e histórico de movimentos ambientais no recorte geográfico, foram utilizados métodos de geoprocessamento para identificação e delimitação de áreas em pretenso risco, seja ecossistêmico-ambiental ou socioambiental.

A partir dos conhecimentos em métodos de geoprocessamento, utilizar-se-á da análise espacial como mecanismo principal, dividindo a metodologia geral em quatro principais estágios: Macrozoneamento; Classificação das áreas; Pesquisa Topológica de sobreposições das áreas finalisticamente contraditórias; e a Investigação do cenário.

Portanto, partindo de um método quali-quantitativo, a investigação final, após o método de localização das áreas, possui como premissa a dedução dos cenários-locais de riscos ambientais para que pesquisas posteriores consigam compreender quais os riscos e as causas dos problemas enfrentados pela região costeira.

As ferramentas utilizadas nesta pesquisa foram, em geral, o software livre de Sistema de Informação Geográfica QGIS, em sua versão 3.0; camadas vetoriais em arquivo shapefile do município de Florianópolis, especialmente os zoneamentos da camada do Plano Diretor Municipal (PDP 482) e o Zoneamento Ecológico Econômico Costeiro (ZEEC) 
desenvolvidos para o Gerenciamento Costeiro (GERCO) do Estado de Santa Catarina ambos de caráter público. Também foram utilizados o software Google Earth Pro, na análise espaço-temporal de imagens de satélite num lapso de 10 anos; leis e decretos municipais e estaduais, conforme delineados durante a pesquisa. Portanto, como objetivo no que tange aos materiais, optou-se pelo uso de ferramentas livres e gratuitas, de fácil acesso e de dados públicos.

\section{Contextualização da área de estudo}

A área de estudo analisada faz parte da Planície do Campeche, localizada ao sudeste de Florianópolis - SC (Brasil), fronteiriça com o Oceano Atlântico, a leste. Sua área é de aproximadamente $55 \mathrm{~km}^{2}$, e seus limites são: Lagoa da Conceição, Praia da Joaquina, Manguezal do Rio Tavares, Costeira do Pirajubaé e Tapera.

De acordo com o último CENSO (IBGE, 2010) realizado, a população do Campeche se distribuía conforme a tabela 01:

Tabela 1 - Habitantes por localidade, distrito do Campeche

\begin{tabular}{|c|c|}
\hline Localidades/bairros & Habitantes (número em 2010) \\
\hline Campeche central & 3.533 \\
\hline Campeche sul & 4.498 \\
\hline Campeche leste & 4.373 \\
\hline Campeche norte & 3.032 \\
\hline Lagoa Pequena & 1.637 \\
\hline Rio Tavares central & 4.322 \\
\hline Rio Tavares norte & 2.402 \\
\hline Morro das Pedras & 781 \\
\hline Pedrita & 2.280 \\
\hline
\end{tabular}

Fonte: IBGE, 2010. Elaboração: Autor. 
Apesar dos números apresentarem um total populacional em 2010 de pouco mais de 26.000 (vinte e seis mil) habitantes, é sabido que por ser uma região turística, esse número naturalmente aumenta, especialmente em temporadas de verão. Ademais, esse último censo fará em breve uma década, o que também aduz que os números devem ter crescido consideravelmente, diante das dinâmicas de solo e especulação imobiliária intensas no lugar.

O distrito do Campeche, dentro de uma visão conceitual geográfica, comporta-se também como um território. Essa formação se desenvolveu a partir das relações entre os moradores do Campeche e seu espaço de morada, podendo-se afirmar que essas relações baseiam-se na afetividade com esse espaço, o que o torna um espaço vivido (SAMPAIO, 2016, p. 84).

Todavia, quanto ao histórico das aceleradas transformações da paisagem no Campeche, pesquisas e trabalhos acadêmicos discorrem exaustivamente sobre essas mudanças. Como exemplo, relatos de que a região foi sendo tomada pela construção civil nas últimas décadas, através de grandes empreendimentos residenciais e condomínios de apartamentos, causando, portanto, devido às suas peculiaridades ambientais e socioculturais, alterações significativas em seu perfil urbanístico (CONCEIÇÃO, 2013, p. 15).

O processo de ocupação de suas margens vem ocorrendo de forma crescente e desordenada desde meados da década de 1990 (BARBOSA; BURGOS; TIRELLI, 2007 apud CONCEIÇÃO, 2013, p. 29), e tendo como início as modificações de zoneamento então incompatíveis ou questionáveis em relação ao ordenamento e ocupação do espaço geográfico, além de inconsistentes frente às vocações de caráter ecológico, turístico e urbano-paisagístico daquela região (BARBOSA; BURGOS; TIRELLI, 2007, p. 107).

De acordo com o atual Plano Diretor de Florianópolis - SC (figura 3), a atual configuração territorial do Distrito do Campeche ficou distribuída pelos seguintes zoneamentos: 
Figura 3 - Atual zoneamento (municipal) do distrito do Campeche, Florianópolis-SC
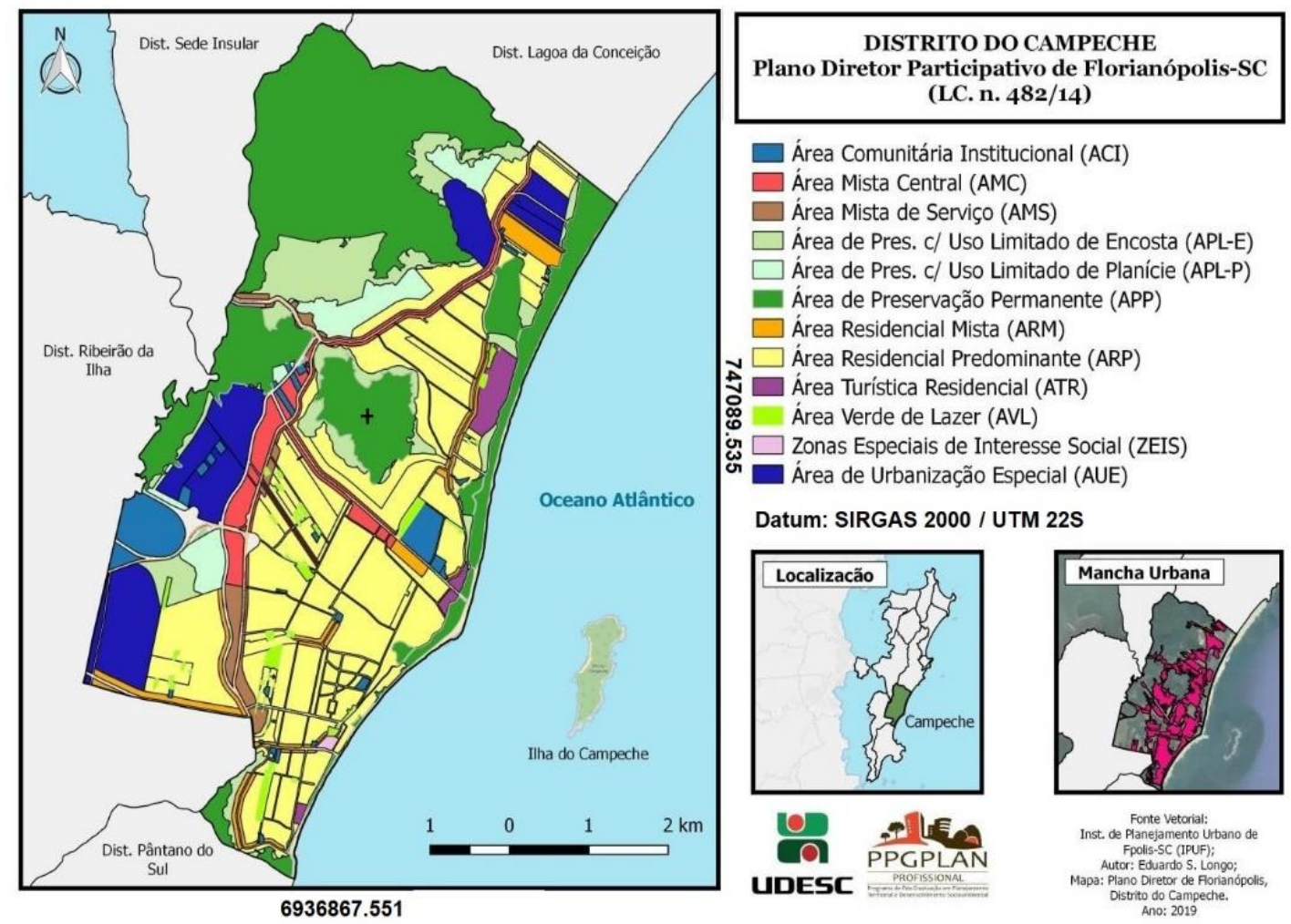

Fonte: Instituto de Planejamento Urbano de Florianópolis - IPUF. Adaptado pelo Autor.

Esses zoneamentos apresentam características marcantes de observação, porém, para manter um enfoque no recorte temático desta investigação, dentre as principais áreas utilizadas como categoria de análise para esta pesquisa: as Áreas Residenciais Predominantes (ARP), em amarelo, de frente à linha de mar, na costa de praia, fazendo margem direta com Áreas de Preservação Permanente (APP), em verde. Ou ainda, áreas de APP coladas em áreas altamente edificantes, sem qualquer tipo de corredor de amortecimento ecológico, ignorando ecótonos.

\section{Metodologia de análise espacial para detecção de zoneamentos conflitantes}

A Análise Espacial (ROSA, 2011) tem por objetivo processar dados geoespaciais que possuem determinados atributos descritivos no intuito de verificar elementos, padrões e tendências que a simples visualização não evidencia. Além de identificar as características 
de um determinado dado, a análise espacial busca verificar a relação entre diferentes dados. Conforme entendimento do DPI/INPE (2006), os dados geográficos não existem sozinhos no espaço, ou seja, por si só - logo, tão fundamental quanto localizá-los é compreender e buscar representar as relações existentes entre os variados dados então observados.

Para esta pesquisa e sua finalidade foram utilizadas algumas das ferramentas de geoprocessamento disponibilizadas através do software QGIS, em sua versão 3.0 (Girona). Após uma série de reflexões e testes, o método completo ficou composto de quatro estágios/etapas principais, as quais cada uma possui suas próprias especificidades e conhecimentos. Portanto, para a identificação das áreas no distrito do Campeche com pré-disposição aos conflitos socioambientais, a partir do método de Geoprocessamento chamado Análise Espacial, aplicaram-se as seguintes etapas, conforme a figura 4:

Figura 4 - Método proposto pelo autor para identificação de zonas costeiras pré-dispostas a conflitos socioambientais

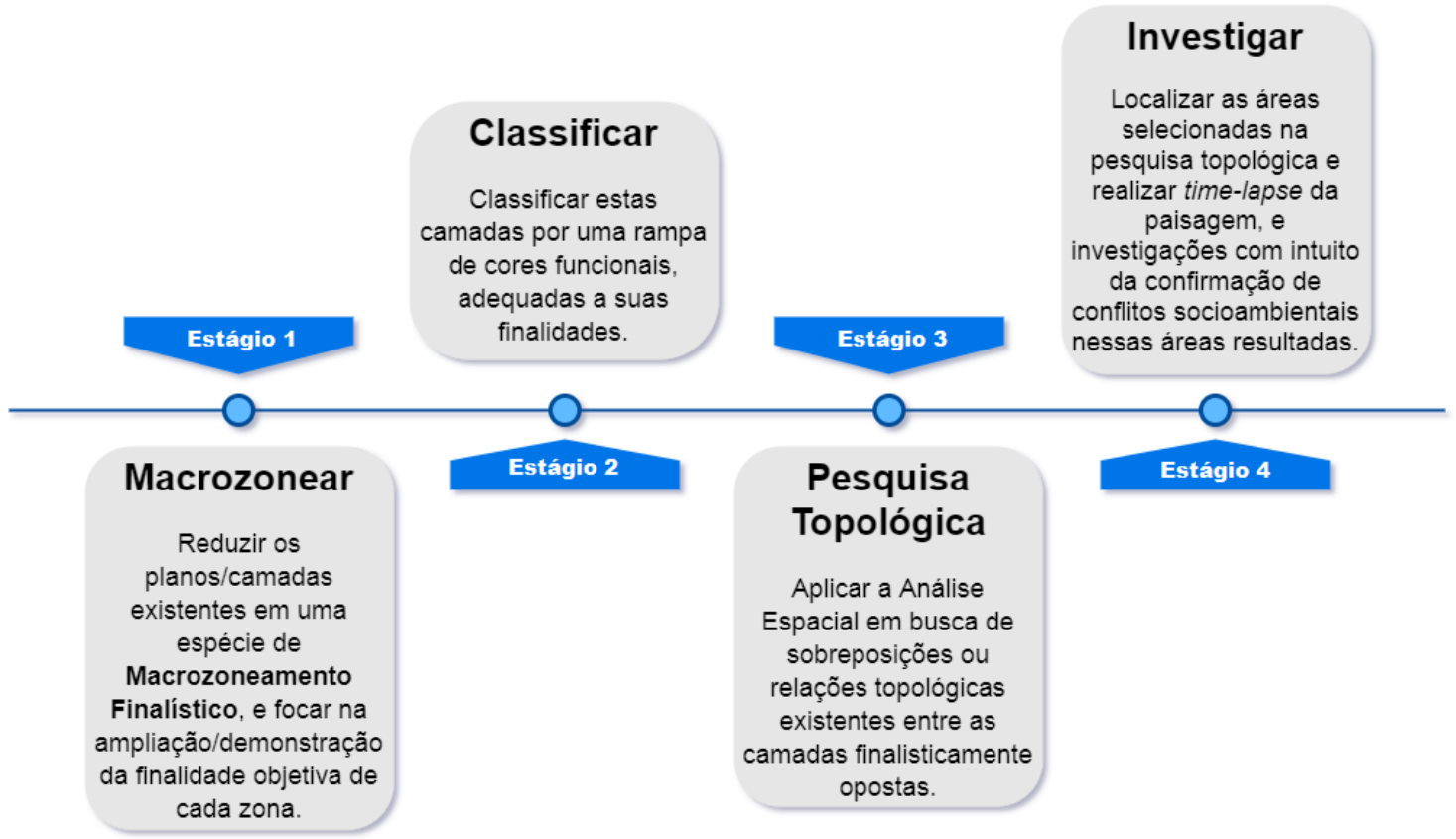

Fonte: Autor. 


\section{Estágio 01 - macrozoneamento:}

Neste primeiro estágio organizaram-se as camadas vetoriais dispostas conforme as próprias diretrizes legais originárias e seus zoneamentos. Utilizando-se do software de geoprocessamento, foram configuradas as camadas e arquivos shapefile no formato de macrozoneamento, possibilitando uma melhor interpretação das finalidades de cada zona, quando analisadas nas próximas fases do método.

Por exemplo, nesta pesquisa o método é aplicado no Distrito do Campeche, em Florianópolis - SC. As duas camadas vetoriais de zoneamento utilizadas foram a de Plano Diretor (FLORIANÓPOLIS, 2014) e o Zoneamento Ecológico Econômico Costeiro (ZEEC) do setor 3 do Estado de Santa Catarina. Nesta fase então é necessário, como premissa, uma primeira preparação destas camadas.

As camadas receberam um recorte (clip), enfatizando apenas o território correspondente à fração/porção do distrito administrativo do Campeche. Após essa seleção e recorte, aplicou-se a simbologia de macrozoneamento, já originada no arquivo shapefile desenvolvido pelo poder público, contendo as classes e enquadramentos dessas zonas $^{1}$ (conforme Figura 6 - ZEEC).

No caso da outra camada trabalhada, a do Zoneamento Municipal (Plano Diretor), a Lei 482/2014 chama de Macro Áreas, o que pode ser compreendido como Macrozoneamento, e de acordo com seu Art. 42., há três Macro Áreas (Figura 05):

§ $1^{\circ}$ Macro Áreas de Usos não Urbanos, com a função precípua de abrigar e desenvolver a biodiversidade: Área de Preservação Permanente (APP), Unidade de Conservação (UC), Áreas de Elementos Hídricos (AEH);

§ $2^{\circ}$ Macro Áreas de Transição, que permitem usos urbanos de baixa densidade com a função de proteger as Áreas de Usos não Urbanos e reservar áreas para expansão urbana em longo prazo: Áreas de Preservação com Uso Limitado (APL), Área Residencial Rural (ARR), Área de Urbanização Especial (AUE);

\footnotetext{
1 Legislação do Estado de Santa Catarina. Anexo do Decreto Estadual 5010: Disponível em: http://www.spg.sc.gov.br/visualizar-biblioteca/acoes/gerco/legislacao-estadual/87-anexo-do-decretoestadual-5010/file. Acesso em: 10 jan. 2020.
} 
$\S 3^{\circ}$ Macro Áreas de usos Urbanos, destinadas prioritariamente às funções da cidade: Área Residencial Predominante (ARP), Área Residencial Mista (ARM), Área Mista de Serviço (AMS), Área Mista Central (AMC), Área Turística Residencial (ATR), Área Turística e de Lazer (ATL), Área Comunitária Institucional $(\mathrm{ACl})$, Área Verde de Lazer $(A V L)$, Área de Estudo Ambiental (AEA), Área Residencial Cultural (ARC), Zonas Especiais de Interesse Social.

Ressalta-se que a forma como o legislador organizou algumas dessas zonas dentro de determinadas macro áreas gera reflexão e crítica por parte deste autor, entretanto, isso não será abordado neste estudo, pois o foco é apontar incompatibilidades entre as zonas assim dispostas (como estão).

\section{Estágio 02 - classificação:}

Após análise e interpretação dos zoneamentos pesquisados, e da devida organização de suas macro áreas, aqueles foram classificados conforme suas finalidades objetivas e gerais, ou seja, quais seriam suas principais premissas. Como exemplo, no ZEEC, de acordo com os parâmetros legais estipulados pelo anexo I do Decreto Estadual 5.010, as Zonas de Preservação Permanente (ZPP) possuem caráter Non aedificandi, ou seja, vedada qualquer forma de parcelamento do solo, edificações e construções. Portanto, essas zonas foram classificadas com a cor verde, simbolizando suas especificidades.

Da mesma forma, as zonas possuidoras de características de expansividade construtiva, e caráter modificador/transformador, foram demarcadas com a cor vermelha. E as outras zonas e suas especificidades gerais demarcadas em laranja ou roxo.

No caso da classificação simbólica do ZEEC há quatro cores, conforme figura 5: 
Figura 5 - ZEEC e tipos de enquadramento no distrito do Campeche, Florianópolis - SC

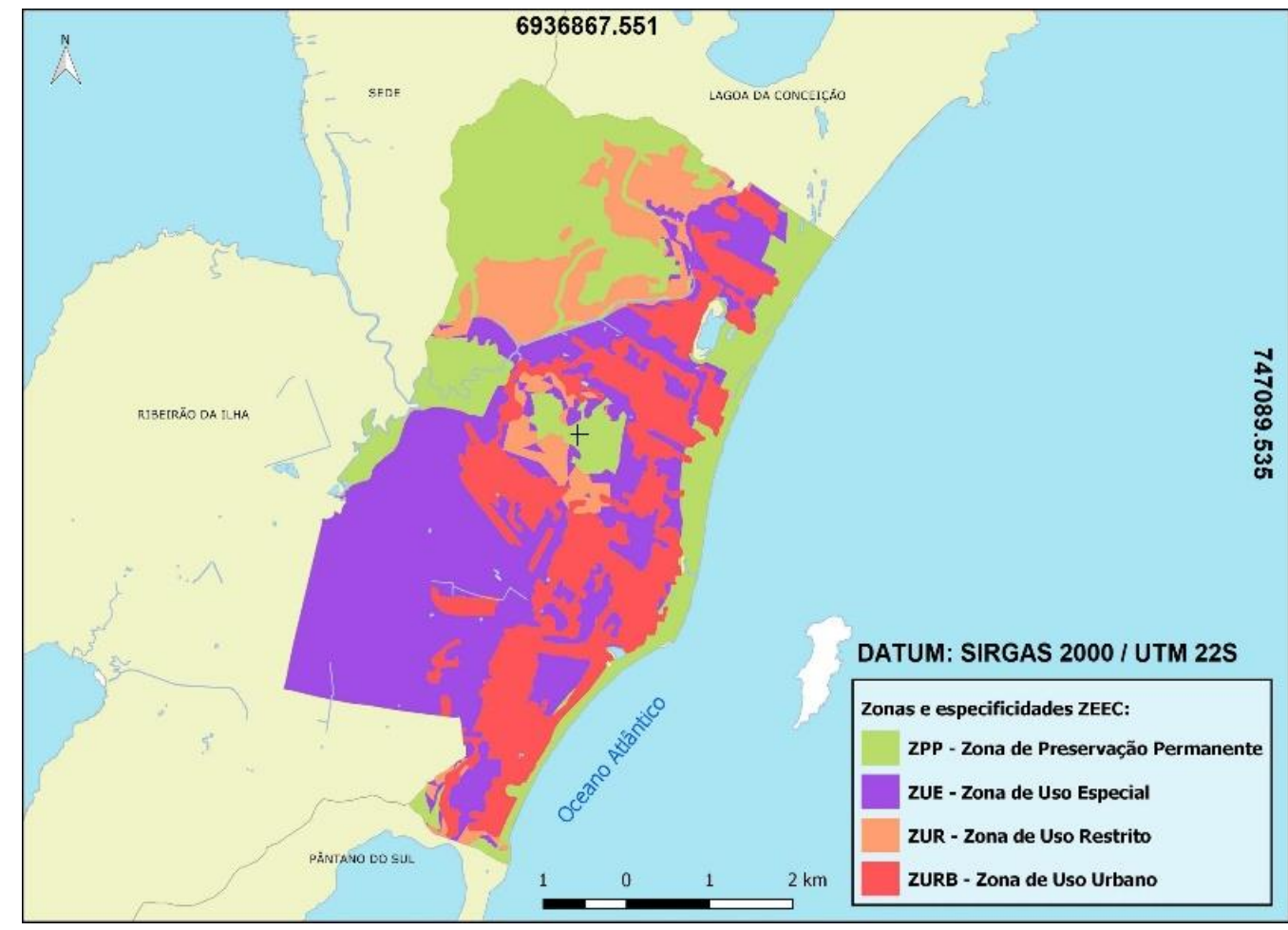

Fonte: Autor / Adaptado dos dados do ZEEC - Secretaria de Estado do Planejamento de Santa Catarina.

As macro áreas do PDP482, apresentadas pela figura 6, ficaram classificadas simbolicamente por três cores: verde, simbolizando as áreas de uso não urbano; roxo, simbolizando áreas de transição ou uso de baixa intensidade; e vermelho, como áreas de uso urbano (caráter intenso de modificação/transformação). 
Figura 6 - Macrozoneamento Plano Diretor Municipal

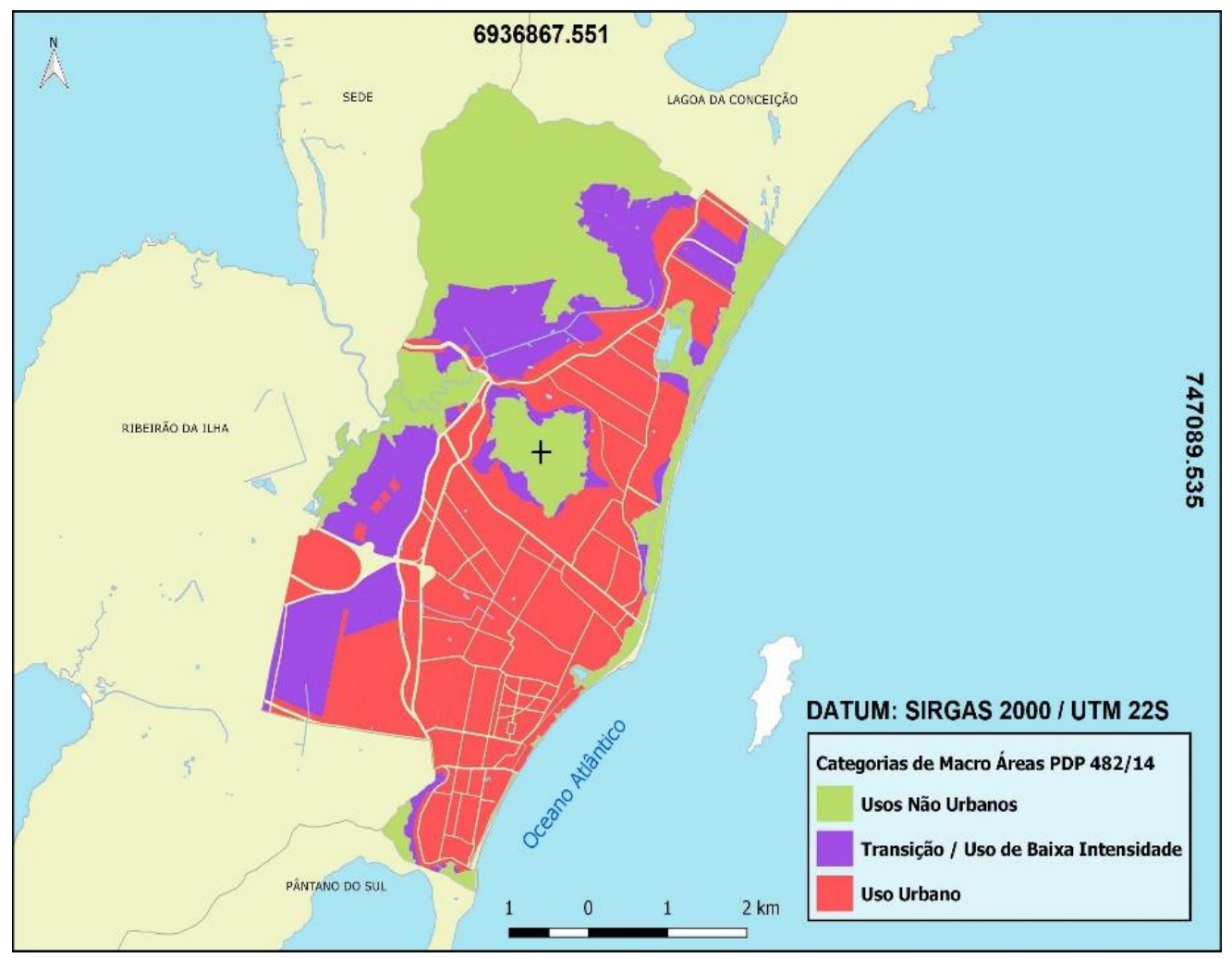

Fonte: Autor / Adaptado dos dados do Plano Diretor Municipal de Florianópolis, SC - IPUF.

Portanto, em ambas as camadas territoriais, as cores verde e vermelho tornam-se uma espécie de categoria de análise a partir de suas finalidades criadoras.

\section{Estágio 03 - pesquisa topológica:}

Nesta etapa do método, utilizam-se as ferramentas de Análise Espacial através do software QGIS, mais precisamente a função seleção por localização (Select By Location), em que o retorno da investigação de sobreposição de Macro Áreas em vermelho do PDP sobre as verdes do ZEEC resulta nas áreas de coloração amarelada, conforme a figura 7 a seguir: 
Figura 7 - Seleção por localização de sobreposição de camadas. Em amarelo, as camadas retornadas do método, onde áreas vermelhas do PDP sobrepõem as verdes do ZEEC

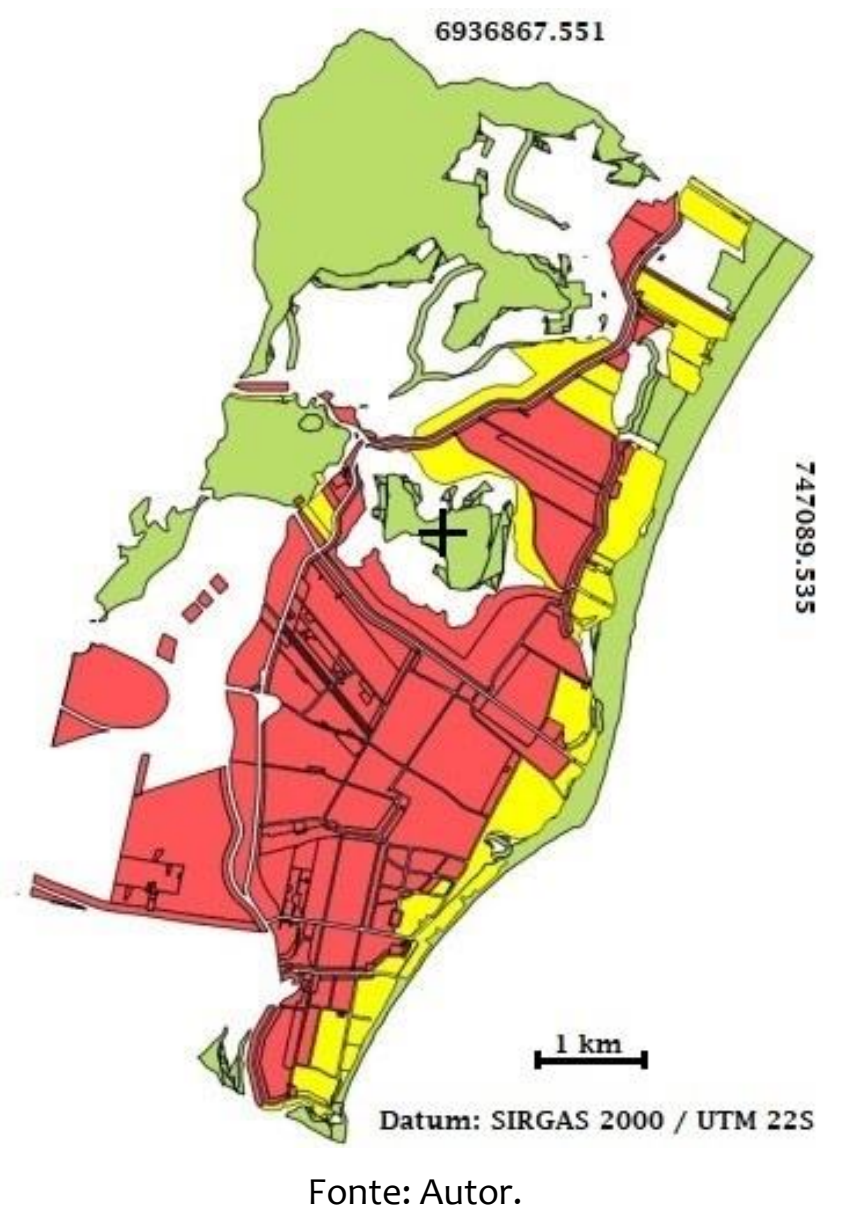

Esta etapa metodológica possui como objetivo a localização de sobreposições geográficas entre zoneamentos com finalidades opostas ou controversas. Portanto, partindo da premissa de que as zonas vermelhas, quando sobrepostas ou coladas às zonas verdes, colocam em risco de alguma forma a segurança socioambiental daquele território, é possível observar que as zonas costeiras retornadas em amarelo merecem destaque quanto às pesquisas e investigações de possíveis conflitos (etapa posterior).

Qualifica-se como segurança socioambiental a presença de vegetação nativa no tocante às áreas costeiras delimitadas pelo Zonamento Ecológico Econômico Costeiro 
(ZEEC) e as Áreas de Preservação Permanente (APP), atuando aquelas como agentes termoreguladores de temperaturas e do microclima da localidade, também como área de necessária defesa ao equilíbrio ecossistêmico, além de todo seu valor paisagístico à região - ou seja, não só há necessidade de proteção da vegetação por seus aspectos diretos, como também dos indiretos, uma vez que o próprio ser humano sofre as consequências da desarmonia entre elementos socioambientais.

\section{Estágio 04 - investigação:}

O último estágio do método é composto por uma investigação de característica empírica/material, com auxílio das camadas criadas a partir da análise espacial em sintonia com imagens de satélite, podendo ainda haver pesquisas em campo para observação e relato do contexto, e até mesmo buscas por informações e notícias locais sobre a região que gerem indícios para aprofundamento das investigações.

Portanto, a partir da camada de retorno das sobreposições (figura 8), configurando-a com $50 \%$ de transparência, será possível observar áreas com maior tendência a conflitos ou problemas ambientais, por conta da contradição veemente entre áreas de caráter edificante e áreas verdes de proteção ambiental ou sensibilidade ecossistêmica: 
Figura 8 - Camada de sobreposição de áreas edificantes com transparência em relação às

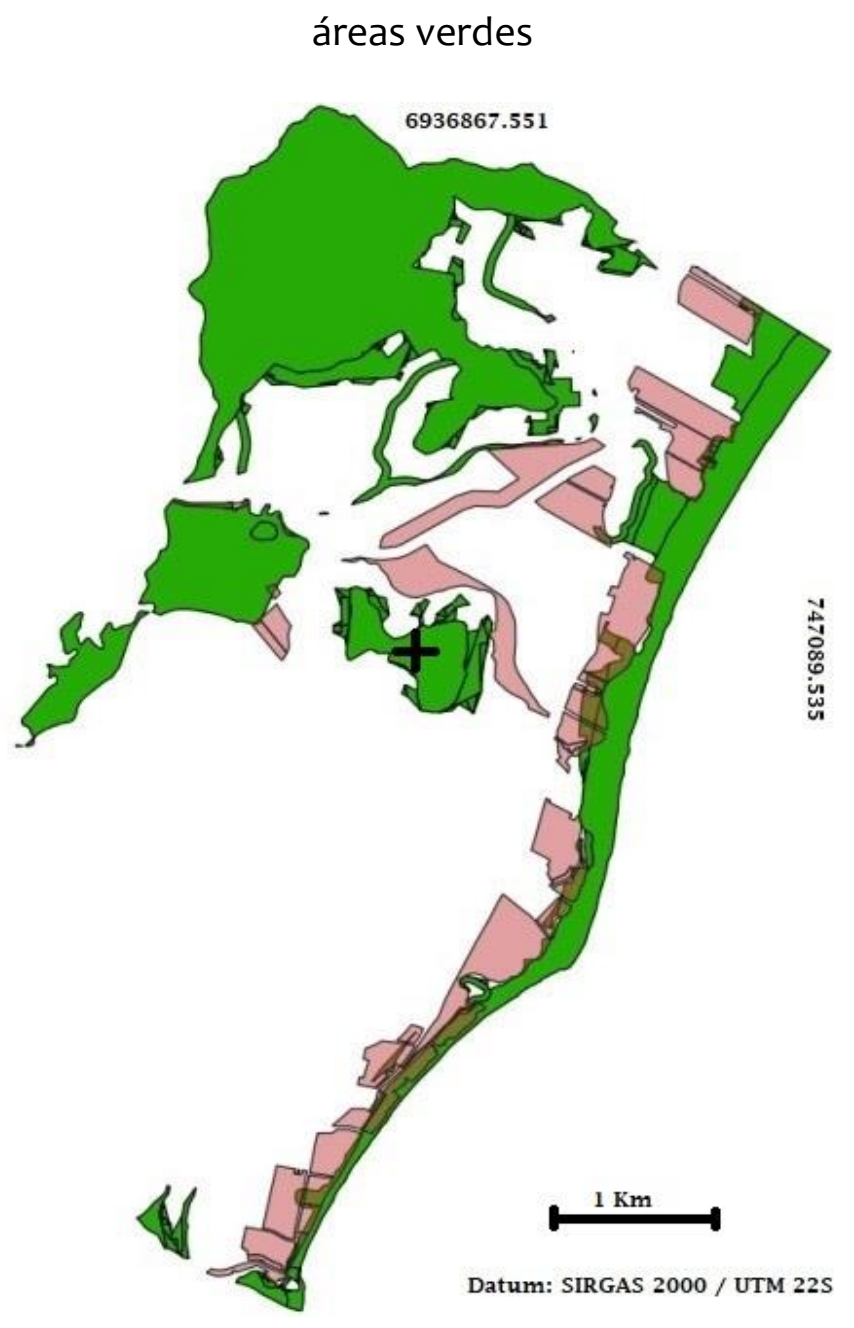

Fonte: Autor.

Por último, torna-se relevante a observação das camadas resultantes do método sobre imagens de satélite no Google Earth Pro, analisando alguns locais então selecionados pela análise espacial para a realização de uma perspectiva históricocomparativa. No caso desse recorte, optou-se por um lapso temporal de dez anos, em razão de ser um considerável intervalo entre planos e zoneamentos. 


\section{Resultados e discussões}

Ao aplicar o método proposto em determinado distrito administrativo localizado em uma região costeira, e utilizando como premissa de análise espacial as duas principais camadas vetoriais de zoneamento responsáveis pelo ordenamento territorial do distrito (Plano Diretor e ZEEC), foi possível observar ao menos cinco locais evidentes onde nos últimos dez anos houve [e está havendo] um avanço explícito de edificações na direção da praia e de áreas sensíveis de costa e vegetação, podendo servir de área de análise quanto a reflexos de microclimas, e impactos ao ecossistema local por consequência das transformações/modificações na paisagem.

No tocante as áreas amareladas retornadas conforme as figuras 9 a 13, a seguir, (sobreposição de camadas com finalidades opostas) há a presença de edificações, em geral de alto padrão aquisitivo, de até quatro pavimentos, que apesar do Plano Diretor Municipal caracterizar a área como Turística Residencial, haja vista o conhecimento empírico de campo e análises pelo Google Street View, foi possível confirmar que trata-se de condomínios multifamiliares com perfil residencial e de alto padrão.

Ademais, ratifica-se que as áreas em vermelho representam áreas de zoneamento com viés construtivo, áreas residenciais predominantes e turísticas residenciais constantes no zoneamento urbano do Plano Diretor Municipal de Florianópolis. As áreas verdes, conforme explicado em momento oportuno anteriormente nesta pesquisa, possuem função de proteção e são destinadas à ZEEC, ou seja, sem perfil e caráter de possibilidade construtiva do ponto de vista da gestão costeira.

Entretanto, as áreas amareladas são produtos da sobreposição entre as vermelhas e verdes, ou ainda, produtos da falta de comunicação e entendimento de escalas entre aquelas, e onde é possível observar em campo - após a utilização do método de análise espacial proposta nesta pesquisa - que houve um fluxo de construções no sentido das áreas que necessitam ser protegidas - conforme as figuras a seguir. 
Metodologia para detecção de áreas socioambientalmente vulneráveis: o caso do distrito do Campeche, no município de Florianópolis - SC, Brasil

Eduardo Schmidt Longo, David Valença Dantas,

Figura 9 - Da esquerda para direita: 2009 e 2019, dez anos de diferença entre os zoneamentos

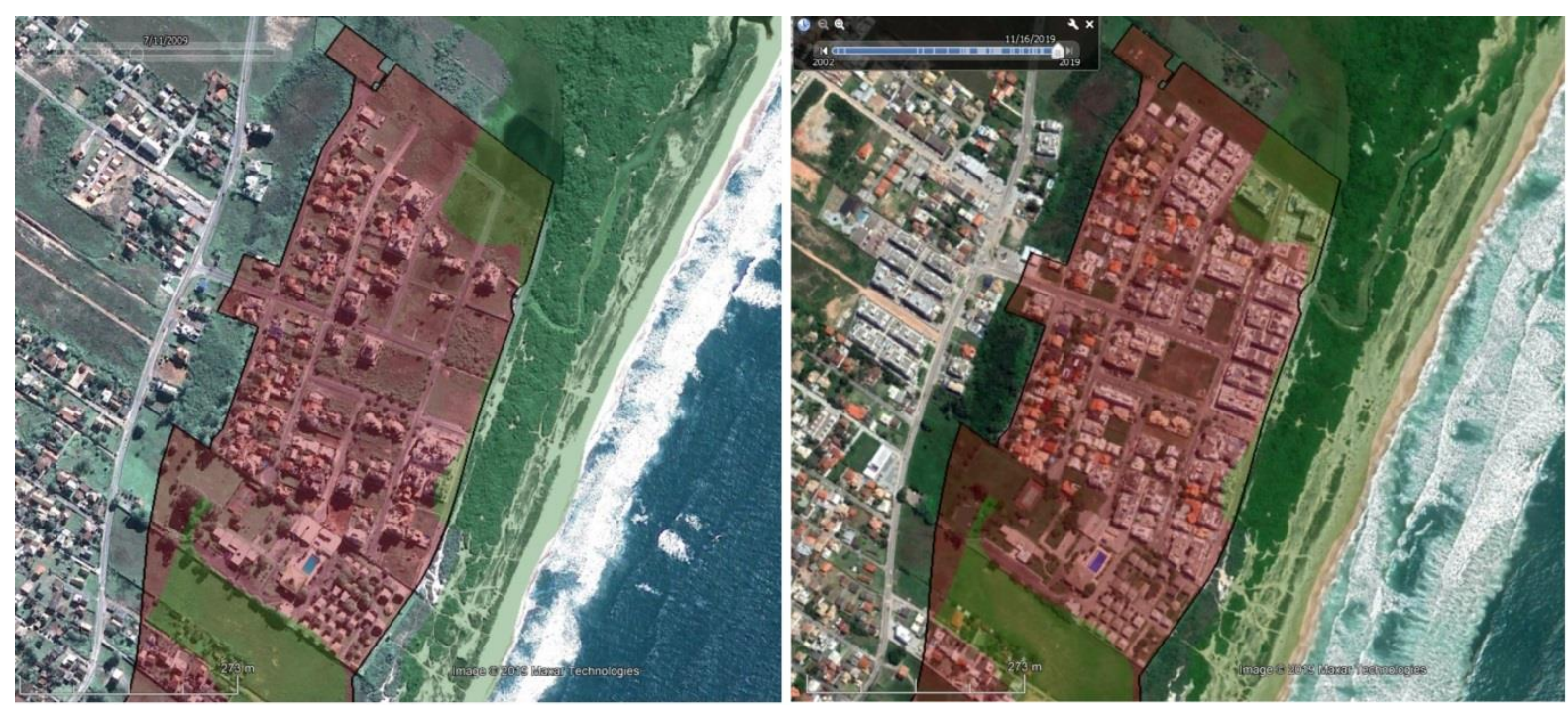

Fonte: Autor.

Figura 10 - Da esquerda para direita: 2009 e 2019, dez anos de diferença entre os zoneamentos

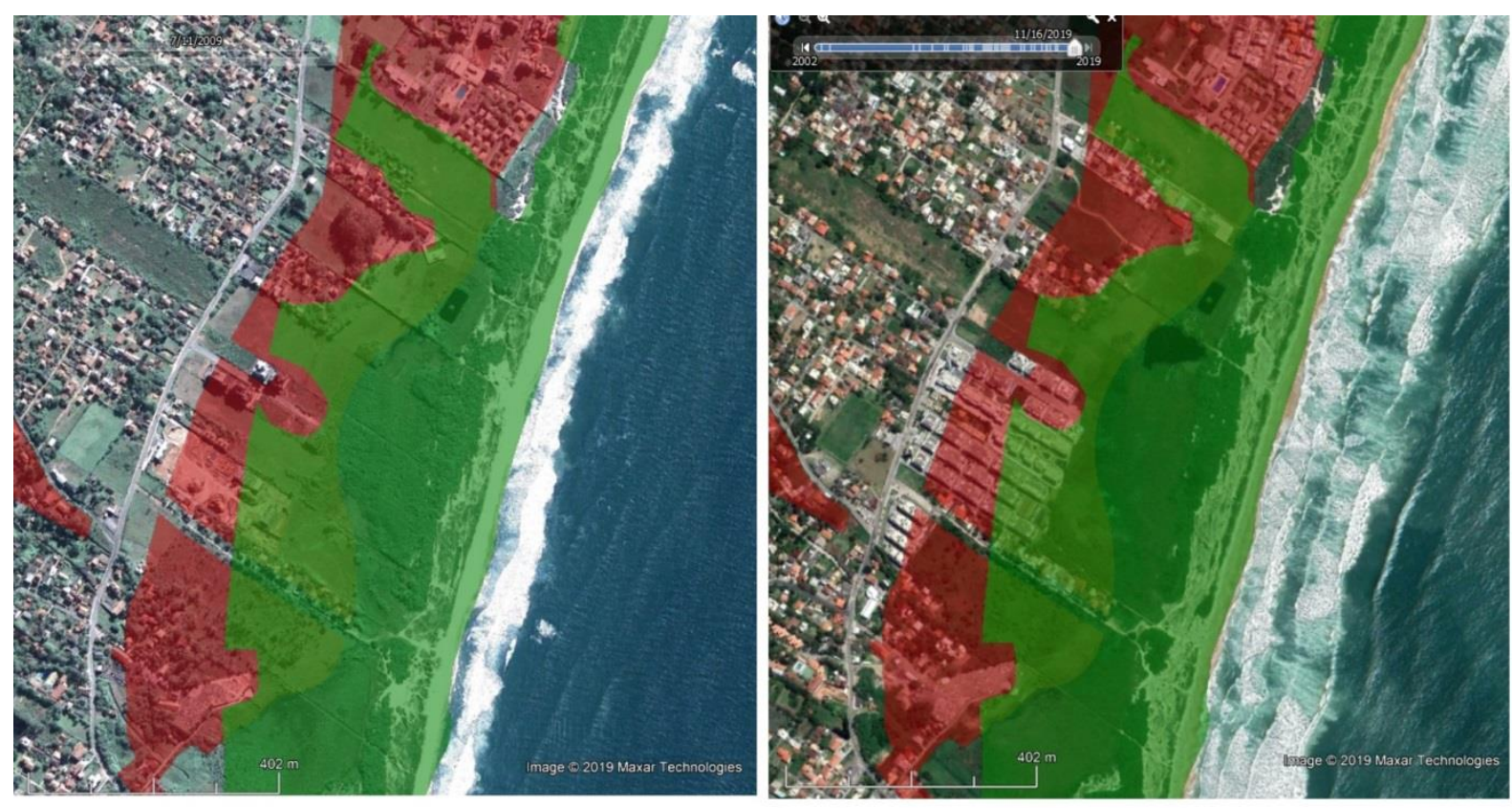

Fonte: Autor. 
Metodologia para detecção de áreas socioambientalmente vulneráveis: o caso do distrito do Campeche, no município de Florianópolis - SC, Brasil

Eduardo Schmidt Longo, David Valença Dantas,

Figura 11 - Da esquerda para direita: 2009 e 2019, dez anos de diferença entre os zoneamentos
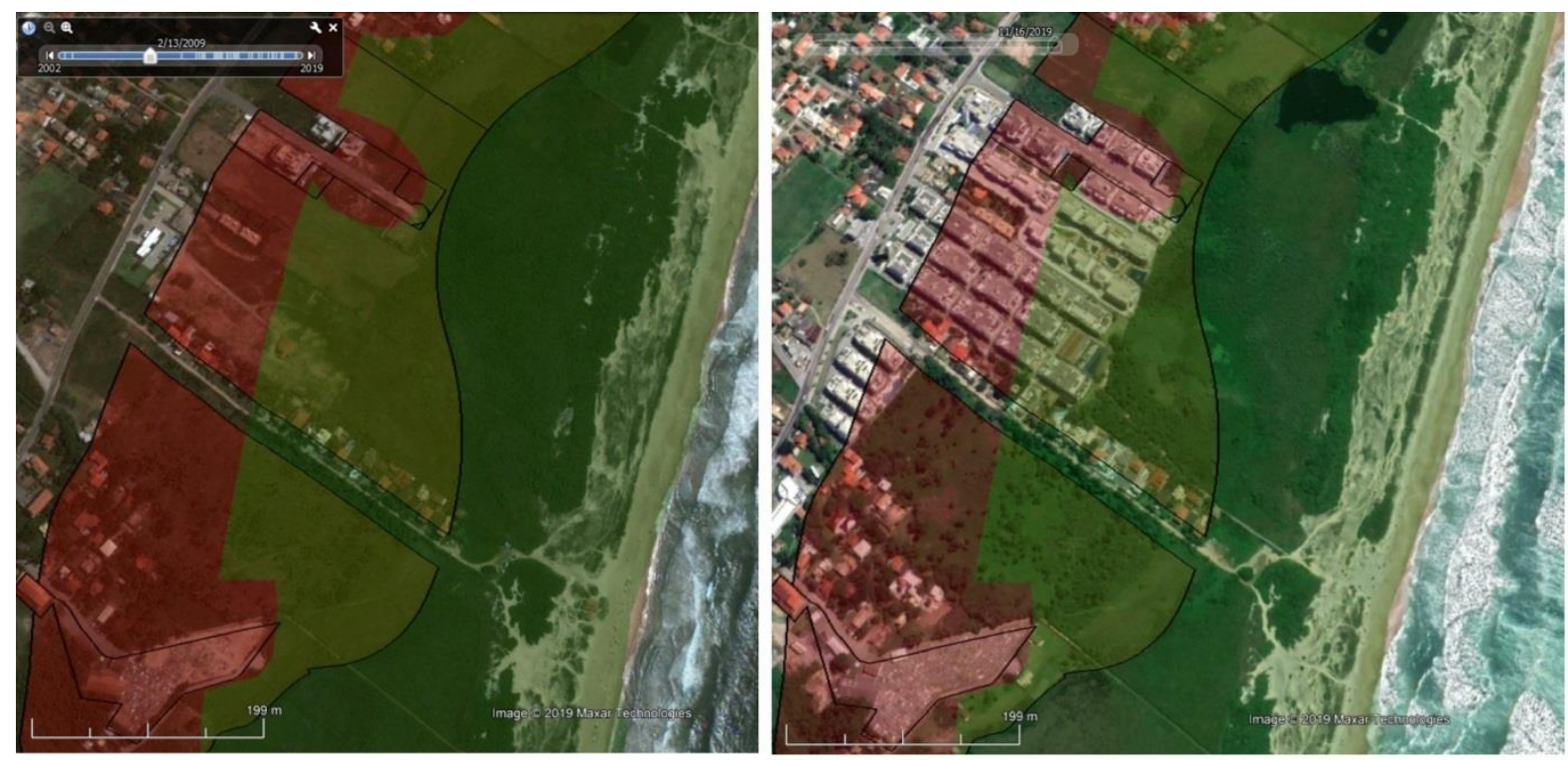

Fonte: Autor.

Figura 12 - Da esquerda para direita: 2009 e 2019, dez anos de diferença entre os zoneamentos
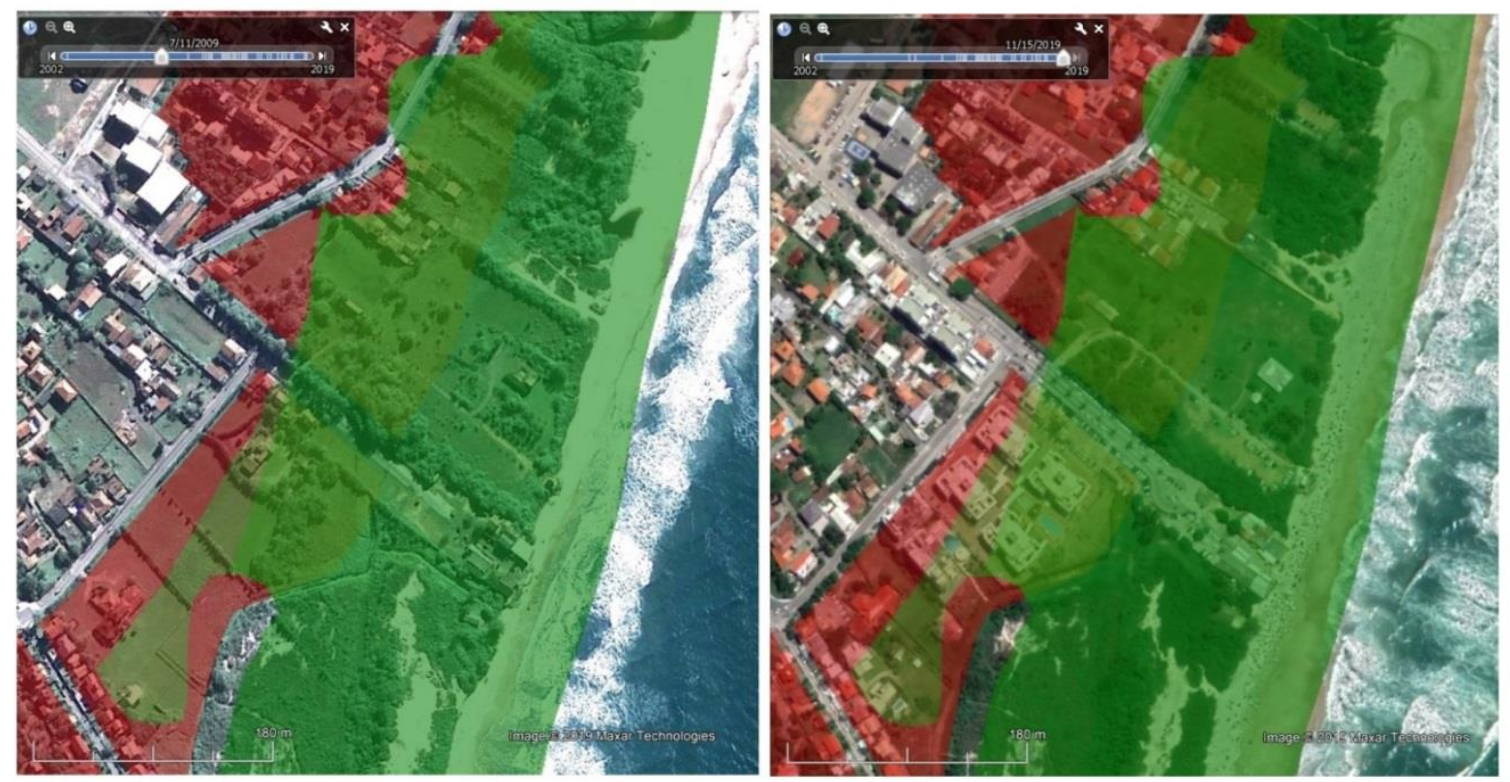

Fonte: Autor. 
Figura 13 - Da esquerda para direita: 2009 e 2019, dez anos de diferença entre os zoneamentos
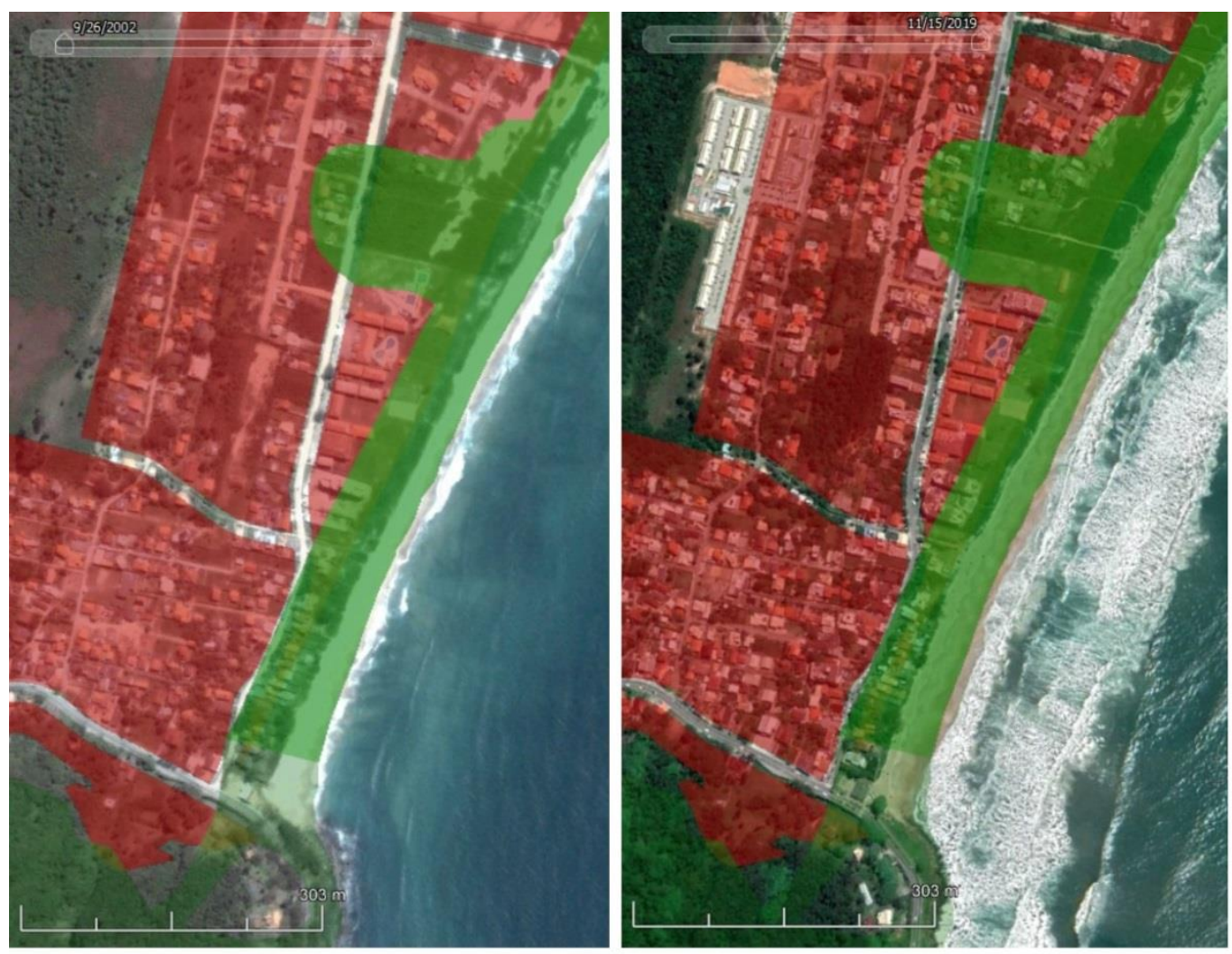

Fonte: Autor

Planejar, por si só, nos remete à ideia de uso de metodologias, ferramentas, plataformas e/ou instrumentos para o ato de organização e aplicação das ideias. Logo, um desses meios para a finalidade do planejamento encontra-se nos chamados zoneamentos. Ou ainda, o zoneamento deve ser a consequência do planejamento dos espaços geográficos ocupáveis e não ocupáveis (RECH; RECH, A., 2013, p. 35).

Para Sanches (1992, p. 19), zonear é um conceito geográfico que significa desagregar um espaço em zonas ou áreas específicas. Da mesma forma que na utilização da expressão planejamento, o termo zoneamento pode variar de acordo com suas características e finalidades propositivas - ou seja, pode haver zoneamento ambiental, urbano, rural, ecológico, entre outros, onde cada qual servirá à suas próprias diretrizes legais e políticas. Em síntese, o zoneamento define a função social da terra e da propriedade (RECH; RECH, A., 2013, p. 169). 
De forma geral, para gestão e planejamento do espaço urbano e meio ambiente [onde um está inserido interseccionalmente ao outro], o Estado utiliza uma série de instrumentos legais, debatidos e elaborados no decorrer do tempo, entre diversos atores e diante de muitos conflitos. De acordo com Rech e Rech (2013, p. 9), a preservação do meio ambiente, segundo a Constituição, tem duas finalidades: $1^{\circ}$ - Assegurar o direito subjetivo do cidadão a um ambiente ecologicamente equilibrado, como forma de assegurar a própria dignidade humana; $2^{\circ}$ - Preservar a biodiversidade, como ferramenta de preservação da vida.

Logo, uma das preocupações do planejamento quanto à ocupação e parcelamento do solo, numa perspectiva legal, pressupõe preliminarmente uma imprescindível dimensão quanto à segurança ecológica diante da ocupação humana - entendendo o ser humano como agente ativo e passivo das transgressões. Sobre essa via-dupla do ser humano sobre o meio em que vive:

Apenas quando as águas invadem as casas e a montanha desce levando moradias, o homem se dá conta de que desrespeitou a natureza, que não construiu em local ambientalmente correto. (RECH; RECH, A., 2013, p. 22)

No recorte geográfico (área de análise proposta), a presente pesquisa selecionou cinco pontos, em que foi observado algum tipo de possível sobreposição de distintos zoneamentos com conceitos opostos. Ou seja, dentre os cinco pontos, é possível averiguar que uma área residencial predominante ou uma área turística residencial, que são zonas demarcadas pelo plano diretor municipal, avançam em direção às zonas de preservação permanente (ZPP), então demarcadas pelo instrumento do gerenciamento costeiro - o zoneamento ecológico econômico costeiro (ZEEC) - uma vez que não há uma comunicação ou aparente relação de influência entre aquelas e as Áreas de Preservação Permanente.

Esse tipo de avanço, independente da "calibragem" que a vetorização e o mapeamento das zonas denotem (escala de trabalho), merece substancialmente uma apreciação dos atores locais, como forma inclusive de fiscalização e feedback para uma 
averiguação real sobre a possibilidade dos fatos, vindo as informações diretamente de quem vive além da barreira do visual e do instrumental político-administrativo.

Dentre os zoneamentos do plano diretor que podem conter áreas que afetam, ou colocam as áreas verdes e ecossistêmicas em "estado de alerta", encontram-se: (ARM) Áreas Residenciais Mistas, (ARP) Áreas Residenciais Predominantes e as (ATR) Áreas Turísticas Residenciais.

Ademais, diante de um extenso litoral, e das dificuldades encontradas para o levantamento de dados de localização e fiscalização de conflitos socioambientais, a metodologia proposta nesta pesquisa pode servir como ferramenta para otimização deste trabalho, quando a partir do método proposto de análise espacial possibilita-se identificar áreas de zoneamentos com finalidades opostas então sobrepostas.

Adentrando num outro ponto necessário da discussão, e propondo reflexões futuras, por conta de lacunas quanto à sensibilidade de respeitar ecótonos e zonas de amortecimento entre áreas edificantes em detrimento das áreas verdes e/ou de territorialidades sistêmicas do ponto de vista ecológico, o poder público abre "brechas" para discussões quanto à legitimidade das modificações da paisagem.

Assim, conforme as figuras 14 e 15 confeccionadas, insere-se nesta pesquisa como sugestão de ideia para uma outra pesquisa futura, a utilização dos cinco cenários identificados como proposta de "locais de observação-participativa" ou pontos de coleta de feedbacks participativos (Ex.: através de um sistema de informações geográficas para participação popular - PPGIS), na busca pela localização e confirmação de conflitos que podem ocorrer no dia a dia do planejamento e vida de uma cidade costeira por conta das incoerências de planos e zoneamentos. Ou seja, ouvir o ator local a respeito das transformações daqueles territórios identificados pelo método.

Com base nisso, projeta-se o recorte geográfico selecionado pelo método proposto nesta pesquisa como cenário de questionamentos e reflexões futuras sobre as transformações da paisagem, podendo ser utilizados esses pontos como cenários de questionário participativo com moradores da região em uma pesquisa futura, pretendendo compreender a percepção e opinião de atores locais sobre essas zonas de 
discussão conceitual, como uma outra etapa então do planejamento territorial e compreensão das dinâmicas do ambiente socialmente construído.

Figura 14 - Áreas de observação-participativa. Pontos 01, 02 e 03

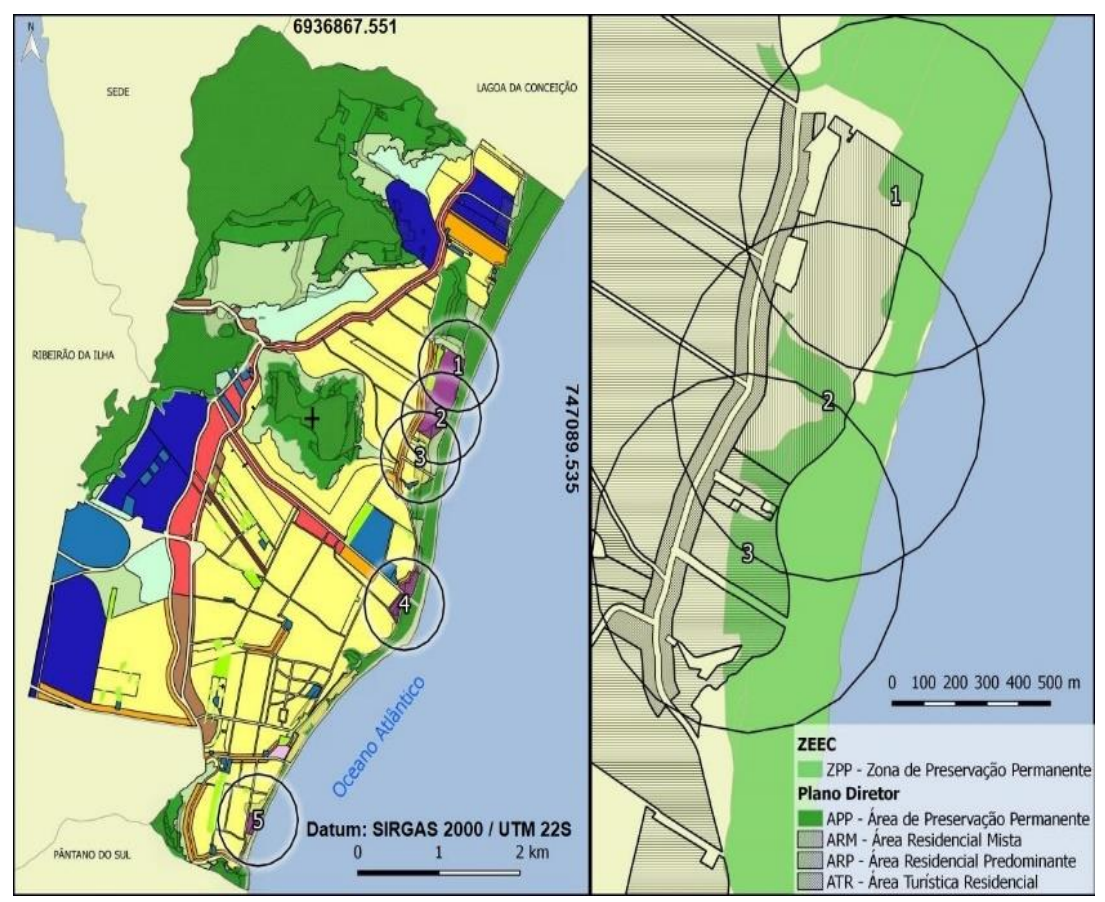

Fonte: Autor.

Figura 15 - Áreas de observação-participativa. Pontos 04 e 05

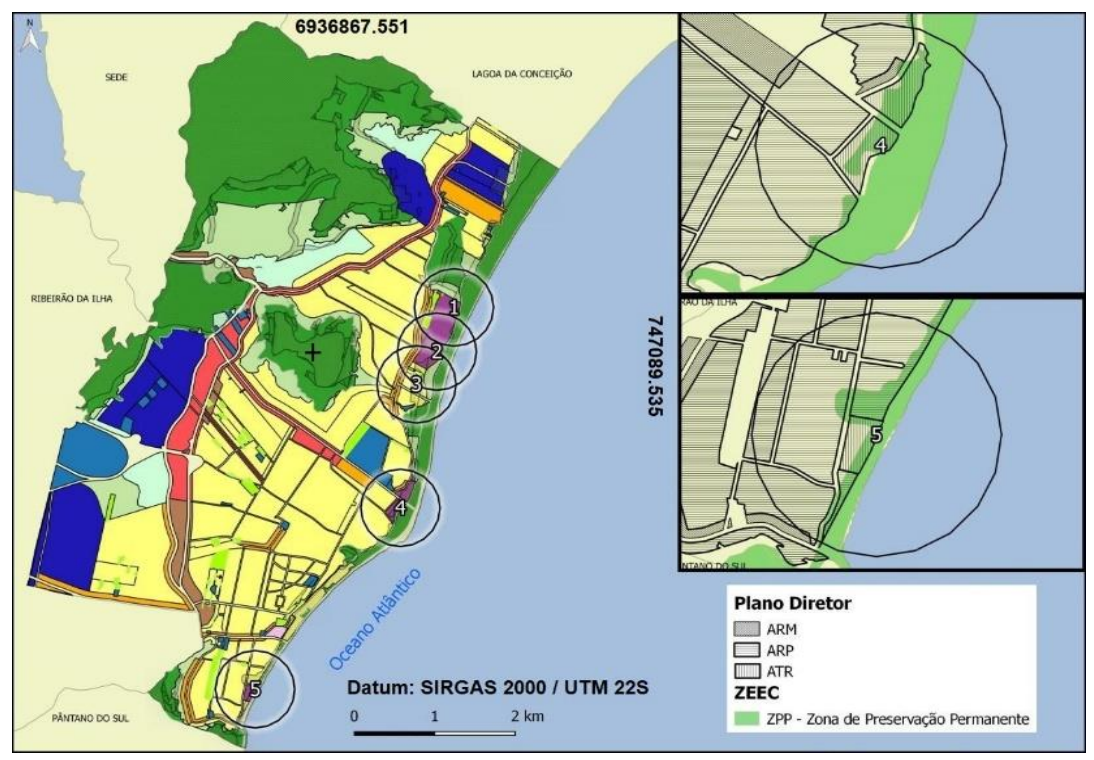

Fonte: Autor. 
Infelizmente, o que se vislumbra é que a dinâmica acelerada do crescimento das cidades gira em torno da propriedade particular, como uma visão de maior atenção. Contudo, ressalta-se que é essencial que a prioridade seja de averiguar o respeito ao direito ao meio ambiente ecologicamente equilibrado, uma vez que é esse meio ambiente uma espécie de "propriedade" comum a todos (RECH; RECH, A., 2013, p. 27) - e por esse motivo torna-se interessante que um método de verificação de áreas de contradição zoneada seja aplicado, otimizando as análises para que posteriormente se compreenda, em campo, a realidade das transformações.

\section{Conclusões}

Minimizar os impactos e efeitos que áreas conflitantes sobrepostas ou limitantes podem ocasionar é um desafio para o poder público (BOSSELMANN, 2010), seja do prisma do planejador, da gestão do território ou até mesmo do judiciário. É urgente que mecanismos para identificação dessas áreas sejam pesquisados e promovidos, uma vez que os desdobramentos da passividade desses equívocos em zoneamentos podem incidir em impactos socioambientais e socioeconômicos negativos, como por exemplo, no caso de recuos de linha de costa [maré cheia - ressacas] em áreas de vegetação devastada para dar lugar a construções, onde estas ações poderão reverberar-se em perdas incalculáveis de patrimônios paisagísticos, patrimônios construídos (seja pelo poder público ou mesmo por particulares), prejuízos a espaços de recreação e cultura de determinadas comunidades, e principalmente, influências irreparáveis ao ecossistema local, entre outros.

Dessa forma, contribuindo para a defesa e gestão sustentável do território, e objetivando a economia de tempo e recursos para uma fiscalização em defesa das zonas costeiras, o método proposto fomenta a otimização das geolocalizações desses ambientes costeiros sensíveis, e possivelmente conflituosos, para dar lugar às posteriores pesquisas e ações na tomada de decisões - como uma pré-análise ao trabalho de campo e investigações mais profundas. 
Por derradeiro, como recomendação a essa metodologia, após a localização das áreas de possíveis conflitos socioambientais pela análise espacial, infere-se que uma segunda etapa de pesquisa pode ser aplicada complementarmente, o chamado levantamento de dados participativos, através de Sistemas de Informação Geográfica para Participação Popular (PPGIS).

\section{Referências}

BARBOSA, Tereza Cristina P.; BURGOS, Raúl; TIRELLI, Janice. (orgs). O Campo de Peixes e os Senhores do Asfalto: memória das lutas do Campeche. Florianópolis: Cidade Futura, 2007.

BORCHERT, Sinéad $M$. et al. Coastal wetland adaptation to sea level rise: Quantifying potential for landward migration and coastal squeeze. Journal of Applied Ecology, v. 55, n. 6, p. 2876-2887, 2018.

BOSSELMANN, Klaus. Direitos humanos, meio ambiente e sustentabilidade. In: SARLET, Ingo Wolfgang. Estado socioambiental e direitos fundamentais. Porto Alegre: Livraria do Advogado, 2010.

BRASIL. [Constituição (1988)]. Constituição da República Federativa do Brasil de 1988. Brasília, DF: Presidência da República, [2016]. Disponível em: http://www. planalto. gov. br/ccivil_03/constituicao/constituicaocompilado. htm. Acesso em: 25 fev. 2020.

BRASIL. Senado Federal. Estatuto da cidade: guia para implementação pelos municípios e cidadãos. Brasília: o Senado, 2001.

CÂMARA, Gilberto; DAVIS, Clodoveu; MONTEIRO, Antônio Miguel Vieira. Introdução à ciência da geoinformação. São José dos Campos: INPE, 2001.

CAVALCANTE, Juliana da Silva Ibiapina; ALOUFA, Magdi Ahmed Ibrahim. Gerenciamento costeiro integrado no Brasil: uma análise qualitativa do plano nacional de gerenciamento costeiro. Desenvolvimento Regional em debate: DRd, v. 8, n. 2, p. 89-107, 2018.

CONCEIÇÃO, Maykon Luiz. O desenvolvimento urbano do bairro do Campeche: um olhar sobre a mudança repentina dos padrões de ocupação do solo. 2013. Trabalho de Conclusão de Curso (Graduação em história) - Universidade Federal de Santa Catarina, Centro de Filosofia e Ciências Humanas, Florianópolis, SC, 2013. 
DIEGUES, Antônio Carlos. Comunidades litorâneas e os manguezais do Brasil. In: ECOLOGIAHUMANA E PLANEJAMENTO COSTEIRO. 2. ed. São Paulo: Nupaub-Usp, 2001. p. $183-216$.

DPI/INPE. Introdução ao geoprocessamento. [Brasília: INPE], 2006.

Disponível em: http://www.dpi.inpe.br/spring/portugues/tutorial/introducao_geo.html>. Acesso em: 25 fev. 2020.

DRUCK, Suzana; CARVALHO, Marília Sá; CAMARA, Gilberto; MONTEIRO, Antônio Miguel. V. Análise espacial de dados geográficos. Brasília: Embrapa, 2004.

FLORIANÓPOLIS. Lei complementar n. 482, de 17 de janeiro de 2014. Institui o plano diretor de urbanismo do município de Florianópolis que dispõe sobre a política de desenvolvimento urbano, o plano de uso e ocupação, os instrumentos urbanísticos e o sistema de gestão. Florianópolis: Prefeitura Municipal, 2014. Disponível em: http://www.pmf.sc.gov.br/arquivos/arquivos/pdf/ 04_02_2014_12.01.39.ae8afdb369c91e13ca6efcc14b25e055.pdf. Acesso em: 25 ago. 2020.

GOURMELON, Françoise; LE GUYADER, Damien; FONTENELLE, Guy. A dynamic GIS as an efficient tool for integrated coastal zone management. ISPRS International Journal of Geo-Information, v. 3, n. 2, p. 391-407, 2014.

HANSEN, Henning Sten; FUGLSANG, Morten. An operational web-based indicator system for integrated coastal zone management. ISPRS International Journal of GeoInformation, v. 3, n. 1, p. 326-344, 2014.

IBGE - INSTITUTO BRASILEIRO DE GEOGRAFIA E ESTATÍSTICA. Censo Demográfico. Rio de Janeiro: IBGE, 2010. v. 23. Disponível em: http://www. censo2010. ibge. gov. br/. Acesso em: 18 mar. 2020.

IBGE - INSTITUTO BRASILEIRO DE GEOGRAFIA E ESTATÍSTICA. Plataforma Cidades. Rio de Janeiro: IBGE, 2020. Disponível em:

https://cidades.ibge.gov.br/brasil/sc/florianopolis/panorama. Acesso em: 19 mar. 2020.

INOUYE, Carlos Eduardo Nakao et al. Modelling the spatial dynamics of urban growth and land use changes in the north coast of São Paulo, Brazil. Ocean \& Coastal Management, v. 108, p. 147-157, 2015.

IPCC. Climate Change 2001: Synthesis Report. A Contribution of Working Groups I, II, and III to the Third Assessment Report of the Integovernmental Panel on Climate Change [Watson, R.T. and the Core Writing Team (eds.)]. Cambridge University Press, Cambridge, United Kingdom, and New York, NY, USA, 2001. 398 pp. 
IPCC. Climate Change 2007: The Physical Science Basis. Contribution of Working Group I to the Fourth Assessment Report of the Intergovernmental Panel on Climate Change [Solomon, S., D. Qin, M. Manning, Z. Chen, M. Marquis, K.B. Averyt, M. Tignor and H.L. Miller (eds.)]. Cambridge University Press, Cambridge, United Kingdom and New York, NY, USA, 2007. 996 pp.

MARTÍNEZ-LÓPEZ, Javier; TEIXEIRA, Heliana; MORGADO, Mariana; ALMAGRO, María; SOUSA, Ana I.; VILLA, Ferdinando; BALBI, Stefano; GENUA-OLMEDO, Ana; NOGUEIRA, Antonio J.A.; LILLEB $\varnothing$, Ana I. Participatory coastal management through elicitation of ecosystem service preferences and modelling driven by "coastal squeeze", Science of The Total Environment, Volume 652, 2019, Pages 1113-1128, ISSN 0048-9697, https://doi.org/10.1016/j.scitotenv.2018.10.309.

MORAES, Antonio Carlos Robert. Contribuições para a gestão da zona costeira do Brasil: elementos para uma geografia do litoral brasileiro. São Paulo: Annablume, 2007.

PETTIT, Christopher J. Use of a collaborative GIS-based planning-support system to assist in formulating a sustainable-development scenario for Hervey Bay, Australia.

Environment and Planning B: planning and design, v. 32, n. 4, p. 523-545, 2005.

PONTEE, Nigel. Defining coastal squeeze: a discussion. Ocean \& coastal management, v. 84, p. 204-207, 2013.

RECH, Adir Ubaldo; RECH, Adivandro. Zoneamento ambiental como plataforma de planejamento da sustentabilidade: instrumentos de uma gestão ambiental, urbanística e agrária para o desenvolvimento sustentável. Caxias do Sul: EDUCS, 2013.

ROSA, Roberto. Análise espacial em geografia. Revista da ANPEGE, v. 7, n. 01, p. 275-289, 2011.

SAMPAIO, Juliana Búrigo. Florianópolis no processo de elaboração de seu plano diretor entre 2006 e 2014: um território em disputa. 2016. Dissertação (Mestrado em Geografia) Universidade Federal de Santa Catarina, Centro de Filosofia e Ciências Humanas, Programa de Pós-Graduação em Geografia, Florianópolis, 2016.

SANCHES, Roberto. Zoneamento agroecológico do Estado do Mato Grosso. Cuiabá: Fundação de Pesquisa Cândido Rondon, 1992.

SANTA CATARINA. Decreto $\mathrm{n}^{\circ}$ 5010, de 22 de dezembro de 2006. Regulamenta a lei $\mathrm{n}^{\circ}$ 13.553 , de 16 de novembro de 2005, que institui o plano estadual de gerenciamento costeiro e estabelece outras providências. Florianópolis: Governo do Estado, 2006. Disponível em: https://leisestaduais.com.br/sc/decreto-n-5010-2006-santa-catarina- 
regulamenta-a-lei-n-13553-de-16-de-novembro-de-2005-que-institui-o-plano-estadual-degerenciamento-costeiro-e-estabelece-outras-providencias. Acesso em: 25 fev. 2020.

TIRELLI, Janice; BURGOS, Raúl; BARBOSA, Tereza Cristina P. O campo de peixes e os senhores do asfalto. Florianópolis: Cidade Futura, 2007.

UNITED NATIONS. Agenda 21: United Nations Conference on Environment and Development, Rio de Janeiro, Brazil, June 1992. New York: United Nations, 1992.

Recebido em: 30/04/2020 Aprovado em: 15/09/2020

Universidade do Estado de Santa Catarina - UDESC Centro de Ciências Humanas e da Educação - FAED PerCursos Volume 21 - Número 46 - Ano 2020 revistapercursos@gmail.com 